\title{
Bioactivities and Chemical Constituents of Essential Oil Extracted from Artemisia anethoides Against Two Stored Product Insects
}

\author{
Jun-yu Liang ${ }^{1,2}$, Wen-ting Wang ${ }^{1}$, Yan-fei Zheng ${ }^{1}$, Di Zhang ${ }^{1}$, Jun-long Wang ${ }^{1}$, \\ Shan-shan Guo ${ }^{2}$, Wen-juan Zhang ${ }^{2}$, Shu-shan $\mathrm{Du}^{2, *}$ and Ji Zhang ${ }^{1}$ \\ ${ }^{1}$ College of Life Science, Northwest Normal University (NO.967 Anning East Road, Lanzhou, 730070, CHINA) \\ ${ }^{2}$ Beijing Key Laboratory of Traditional Chinese Medicine Protection and Utilization, Beijing Normal University (NO.19 Xinjiekouwai Street, Beijing \\ 100875, CHINA)
}

\begin{abstract}
The chemical constituents of the essential oil extracted from Artemisia anethoides and the bioactivities of essential oil against Tribolium castaneum and Lasioderma serricorne were investigated. The main components of the essential oil were 1,8-cineole (36.54\%), 2-isopropyl-5-methyl-3-cyclohexen-1-one (10.40\%), terpinen-4-ol (8.58\%), 2-isopropyltoluene (6.20) and pinocarveol (5.08\%). The essential oil of $A$. anethoides possessed contact and fumigant toxicities against $T$. castaneum adults $\left(\mathrm{LD}_{50}=\mathbf{2 8 . 8 0} \mu \mathrm{g} / \mathrm{adult}\right.$ and $L_{C_{0}}=13.05 \mathrm{mg} / \mathrm{L}$ air, respectively) and against $L$. serricorne $\left(L D_{50}=24.03 \mu \mathrm{g} /\right.$ adult and $L D_{50}=8.04 \mathrm{mg} / \mathrm{L}$ air, respectively). The crude oil showed repellent activity against $T$. castaneum and $L$. serricorne. Especially, the percentage repellency of essential oil was same level with DEET (positive control) against T. castaneum . The results indicated that the essential oil of $A$. anethoides had the potential to be developed as insecticide and repellent for control of $T$. castaneum and $L$. serricorne.
\end{abstract}

Key words: Tribolium castaneum, Lasioderma serricorne, insecticidal toxicity, repellent activity

\section{INTRODUCTION}

The red flour beetle Tribolium castaneum (Herbst) (Coleoptera: Tenebrionidae) and the cigarette beetle Lasioderma serricorne (Fabricius) (Coleoptera: Anobiidae) are the two most common species of the insects in stored product. The secreta of $T$. castaneum can cause the flour to agglomerate, change color and go bad, and the secreta contain the benzoquinone which is a kind of carcinogenic substance. They have the characteristics of rapid reproduction, strong adaptation, and worldwide distribution, so the two species of insects cause significant damage during storage of many crops and products ${ }^{1)}$.

Synthetic chemical pesticides are wildly used and have high efficiency against insects on farms and stored products more than 100 years, but more and more negative ecology and health impacts have attracted people's attention $^{2}$. For example, the overzealous used of synthetic chemical pesticides have caused some species of animal to be in the state of extinction or on the edge of extinction ${ }^{3)}$. Therefore, the available alternatives of synthetic chemical insecticides are required and urgent. Many government en- couraged researchers to study new pesticides which were high-efficiency and low toxicity to mammal and environment ${ }^{4)}$.

It was more than150 years that botanical insecticide was used to protect food crops and stored products from insect pests ${ }^{5}$. Now the botanical insecticides have attracted more and more researchers' interest for the characteristic of fair insecticides, low toxicity and easy biodegradation ${ }^{6,7)}$. Because their highly volatile nature, the plant essential oils are less likely to leave residues on stored products, and many essential oils have been evaluated for insecticidal activity $^{8-13)}$. These favorable properties and studies suggest that we may find new and viable pesticides based on the essential oil.

Artemisia anethoides Mattf. (Compositae) widely distribute in northern China and the resource of the plant is

Abbreviations: A. anethoides: Artemisia anethoides; $\boldsymbol{T}$. castaneum: Tribolium castaneum; L. serricorne: Lasioderma serricorne; RI: Retention Index; GC-MS: Gas ChromatographyMass Spectrometer; FID: flame ionization detector; DEET: N,N-diethyl-3-methyl-benzami; PR: percentage repellency

\footnotetext{
*Correspondence to: Shu-shan Du, Beijing Key Laboratory of Traditional Chinese Medicine Protection and Utilization, Beijing Normal University (NO.19 Xinjiekouwai Street, Beijing 100875, CHINA)

E-mail: dushushan@bnu.edu.cn

Accepted August 30, 2016 (received for review April 7, 2016)

Journal of Oleo Science ISSN 1345-8957 print / ISSN 1347-3352 online

http://www.jstage.jst.go.jp/browse/jos/ http://mc.manusriptcentral.com/jjocs
} 
very abundant. A. anethoides have been used as a substitute of Artemisia capillaris which is famous traditional Chinese medicine ${ }^{14)}$. The bioactivity about essential oil of $A$. anethoides has been not investigated.

In this work, the insecticidal and repellent activities of the essential oil from $A$. anethoides against $L$. serricorne and $T$. castaneum adults will be researched. It was expected to find new botanical pesticides.

\section{MATERIALS and METHODS}

\subsection{Plant material and extraction of essential oil}

The fresh leaves of $A$. anethoides were collected from Lintan county, Gansu Province, China $\left(34^{\circ} 58^{\prime} 18^{\prime \prime} \mathrm{N}\right.$ latitude, $103^{\circ} 39^{\prime} 12^{\prime \prime} \mathrm{E}$ longitude, altitude $2233 \mathrm{~m}$ ) in August 2014. The species was identified by Dr. Liu, Q.R. and the voucher specimen (BNU-dushushan-2014080205) was deposited at the Herbarium (BNU) of College of Resources Science and Technology, Beijing Normal University. The leaves were air-dried and chopped, then weighed to $500 \mathrm{~g}$ and were transferred into a clevenger apparatus equipped with a watercooled oil receiver to reduce overheating artifacts. The hydrodistillation was carried out for $6 \mathrm{~h}$. The distillate was extracted with n-hexane and the essential oil was collected. The extra water was removed by adding anhydrous sodium sulphate. The volumes of pure essential oil were $5.05 \mathrm{~mL}$. The essential oil was stored in airtight containers in refrigerator at $4{ }^{\circ} \mathrm{C}$.

\subsection{Insects}

Tribolium castaneum and Lasioderma serricorne were obtained from laboratory-reared maintained in the dark cabinet of an incubator for the last 2 years. The culture condition is $29 \pm 1^{\circ} \mathrm{C}$ and $70-80 \%$ relative humidity. Two species of insects were reared in glass containers $(0.5$ L) containing wheat flour mixed with yeast $(10: 1, w / w)$. The unsexed insects used in all of the experiments were 1-2 weeks old adults.

\subsection{GC-MS analysis of $A$. anethoides essential oil}

GC instrument (Agilent 6890N) which was equipped with a flame ionization detector (FID) and coupled to a mass spectrometer (Agilent 5973N) was carried out to analysis the constituents of $A$. anethoides essential oil. Capillary column was HP-5MS $(30 \mathrm{~m} \times 0.25 \mathrm{~mm} \times 0.25 \mu \mathrm{m})$. The column temperature was programmed at $60^{\circ} \mathrm{C}$ for $2 \mathrm{~min}$, then risen at $10^{\circ} \mathrm{C} / \mathrm{min}$ to $180^{\circ} \mathrm{C}$ for keeping $1 \mathrm{~min}$, and then risen at $20^{\circ} \mathrm{C} / \mathrm{min}$ to $280^{\circ} \mathrm{C}$ for keeping $15 \mathrm{~min}$. The injector temperature was maintained at $270^{\circ} \mathrm{C}$. The samples ( $1 \mu \mathrm{L}$, dilute to $1 \%$ with hexane) were injected with a split ratio of 1:10. The helium was used as the carrier gas at a flow rate of $1.0 \mathrm{~mL} / \mathrm{min}$. The identification of the constituents were based on comparison of their retention indices
(RI) obtained using n-alkanes $\left(\mathrm{C}_{8}-\mathrm{C}_{24}\right)$. On the other hand depended on their mass spectra with those stored in NIST 05 (Standard Reference Data, Gaithersburg, MD, USA) and Wiley 275 libraries (Wiley, New York, NY, USA) or with mass spectra from the literature ${ }^{15)}$. Relative percentages of the individual constituents of the essential oil were obtained by averaging the GC-FID peak area\% reports.

\subsection{Fumigant toxicity}

The fumigant toxicity of the essential oil against two species of insects was tested as described by Liu and $\mathrm{Ho}^{16)}$. A serial dilution of the essential oil was prepared in $n$-hexane. A Whatman filter paper (diameter $2.0 \mathrm{~cm}$ ) was impregnated with $10 \mu \mathrm{L}$ dilution, and then placed on the underside of the screw cap of a glass vial (diameter $2.5 \mathrm{~cm}$, height $5.5 \mathrm{~cm}$, volume $25 \mathrm{~mL}$ ). The solvent was allowed to evaporate for $20 \mathrm{~s}$ before the cap was placed tightly on the glass vial, each of which contained 10 insects inside to form a sealed chamber. $n$-Hexane was used as a negative control. The MeBr and phosphine were used as positive control against T. castaneum and L. serricorne respectively. Five replicates were carried out for all treatments and controls, and the dead insects were counted after $24 \mathrm{~h}$.

\subsection{Contact toxicity}

The contact toxicity was tested based on the methods described by Liu and $\mathrm{Ho}^{16)}$ against $T$. castaneum and $\mathrm{L}$. serricorne. The essential oil was dissolved in $n$-hexane to prepare a serial testing solution. n-Hexane solvent was the negative control and the pyrethrins was the positive control. Aliquots of $0.5 \mu \mathrm{L}$ of the dilutions were applied topically to the dorsal thorax of two species of insects. Five replicates were implemented for all treatments and controls. The dead insects were counted after $24 \mathrm{~h}$.

\subsection{Repellency tests}

The repellent activity of the essential oil against T. castaneum and $L$. serricorne were investigated based on the method described by Zhang et al. ${ }^{17)}$. Range-finding studies were run to determine the appropriate testing concentrations. The essential oil of $A$. anethoides was dissolved in nhexane to prepare serials of testing solutions with five concentrations $\left(78.63,15.73,3.15,0.63\right.$ and $\left.0.13 \mathrm{~nL} / \mathrm{cm}^{2}\right)$, and $n$-hexane was used as the negative control. Meanwhile a commercial repellent, N, N-diethyl-3-methylbenzamide (DEET) was used as a positive control. All experiments were repeated at least five times. Numbers of the insects present on each strip were counted after $2 \mathrm{~h}$ and $4 \mathrm{~h}$. The value of percent repellency $(\mathrm{PR})$ was calculated with following equation:

$$
\mathrm{PR}(\%)=[(\mathrm{Nc}-\mathrm{Nt}) /(\mathrm{Nc}+\mathrm{Nt})] \times 100
$$

here: Nc was the number of insects present on the negative control half, $\mathrm{Nt}$ was the number of insects present on 
the testing part, and then the averaged PR values and the $\mathrm{SE}$ values were derived.

\subsection{Data analysis}

The data were corrected for control mortality using Abbott's formula. The $\mathrm{LC}_{50}$ (Fumigant toxicity) and $\mathrm{LD}_{50}$ (Contact toxicity) values were calculated by using Probit analysis (IBM SPSS V20.0) ${ }^{18)}$. In repellency tests, means and standard errors were conducted by Microsoft Excel 2007 for Windows XP.

\section{RESULTS and DISCUSSION}

\subsection{Chemical composition of the essential oil}

The essential oil was extracted from the leaves of $A$. anethoides with the yield of $1.01 \%(\mathrm{v} / \mathrm{w})$ and the density of $0.98 \mathrm{~g} / \mathrm{mL} .17$ components were identified in $A$. anethoides essential oil and the sum of their contents were accounted for $98.08 \%$ of the essential oil. The results were listed in Table 1. The main components were 1,8-cineole (36.54\%), 2-isopropyl-5-methyl-3-cyclohexen-1-one (10.40\%), terpinen-4-ol (8.58\%), 2-isopropyltoluene (6.20), pinocarveol
$(5.08 \%)$. There was not literature about the constituent of the essential oil of $A$. anethoides. 1,8-Cineole was rich in essential oil of $A$. anethoides and it was similar with many others artemisia species. For example, the percentage of 1,8-cineole was $22.03 \%, 32.93 \%$ and $39.88 \%$ in the essential oils of Artemisia. argyi, Artemisia. stolonifera and Artemisia. mongolica ${ }^{19-21)}$. 1,8-Cineole may be representative constituent in Artemisia Linn.

\subsection{Fumigant toxicity}

The fumigant toxicity of $A$. anethoides essential oil against $T$. castaneum and $L$. serricorne were listed in Table 2. The essential oil of $A$. anethoides possessed fumigant toxicity with a $\mathrm{LC}_{50}$ value of $13.05 \mathrm{mg} / \mathrm{L}$ air and 8.04 mg/L air against T. castaneum and L. serricorne respectively. When compared with the positive control, the essential oil demonstrated more weak toxicity against two species of insects. Nevertheless, based on similar bioassay tested methods, compared with the fumigant toxicity of other essential oils, the essential oil of $A$. anethoides exhibited stronger toxicity than Litsea cubeba $\left(\mathrm{LC}_{50}=22.97\right.$ $\mathrm{mg} / \mathrm{L}$ air ${ }^{12)}$. The essential oil of $A$. anethoides showed weaker fumigant toxicity than the essential oils that their

Table 1 Chemical constituents of the essential oil derived from A. anethoides.

\begin{tabular}{|c|c|c|c|c|c|}
\hline Peak No. & RI* & RT & Compounds & Chemical formula & Composition (\%) \\
\hline 1 & 978 & 3.954 & 2-Isopropyltoluene & $\mathrm{C}_{10} \mathrm{H}_{14}$ & 6.20 \\
\hline 2 & 1017 & 4.111 & 1,8-Cineole & $\mathrm{C}_{10} \mathrm{H}_{18} \mathrm{O}$ & 36.54 \\
\hline 3 & 1174 & 4.672 & $\beta$-Terpineol & $\mathrm{C}_{10} \mathrm{H}_{18} \mathrm{O}$ & 2.68 \\
\hline 4 & 1126 & 4.899 & p-Menth-2-en-1-ol & $\mathrm{C}_{10} \mathrm{H}_{18} \mathrm{O}$ & 1.39 \\
\hline 5 & 1155 & 5.091 & Pinocarveol & $\mathrm{C}_{10} \mathrm{H}_{16} \mathrm{O}$ & 5.08 \\
\hline 6 & 1167 & 5.254 & $\alpha$-Pinocarvone & $\mathrm{C}_{10} \mathrm{H}_{14} \mathrm{O}$ & 3.77 \\
\hline 7 & 1179 & 5.396 & Terpinen-4-ol & $\mathrm{C}_{10} \mathrm{H}_{18} \mathrm{O}$ & 8.58 \\
\hline 8 & 1184 & 5.517 & $\alpha$-Terpineol & $\mathrm{C}_{10} \mathrm{H}_{18} \mathrm{O}$ & 2.52 \\
\hline 9 & 1251 & 6.021 & 2-Isopropyl-5-methyl-3-cyclohexen-1-one & $\mathrm{C}_{10} \mathrm{H}_{16} \mathrm{O}$ & 10.40 \\
\hline 10 & 1272 & 6.191 & Bornyl acetate & $\mathrm{C}_{12} \mathrm{H}_{20} \mathrm{O}_{2}$ & 0.37 \\
\hline 11 & 1372 & 6.930 & $\alpha$-Copaene & $\mathrm{C}_{15} \mathrm{H}_{24}$ & 0.92 \\
\hline 12 & 1414 & 7.278 & $\beta$-Caryophyllene & $\mathrm{C}_{15} \mathrm{H}_{24}$ & 2.44 \\
\hline 13 & 1479 & 7.740 & Germacrene D & $\mathrm{C}_{15} \mathrm{H}_{24}$ & 4.49 \\
\hline 14 & 1489 & 7.853 & Bicyclogermacrene & $\mathrm{C}_{15} \mathrm{H}_{24}$ & 2.28 \\
\hline 15 & 1527 & 8.088 & 4-(methylthio)-Phenol & $\mathrm{C}_{7} \mathrm{H}_{8} \mathrm{O}_{\mathrm{S}}$ & 4.46 \\
\hline 16 & 1608 & 8.514 & Davanone & $\mathrm{C}_{15} \mathrm{H}_{24} \mathrm{O}_{2}$ & 4.38 \\
\hline \multirow[t]{5}{*}{17} & 1563 & 8.642 & Spathulenol & $\mathrm{C}_{15} \mathrm{H}_{24} \mathrm{O}$ & 1.58 \\
\hline & & & total & & 98.08 \\
\hline & & & Monoterpenoids & & 65.88 \\
\hline & & & Sesquiterpenoids & & 16.09 \\
\hline & & & Others & & 16.11 \\
\hline
\end{tabular}

* RI, retention index as determined on a HP-5MS column using the homologous series of $n$-alkanes. 
Table 2 Fumigant toxicity of $A$. anethoides essential oil against T. castaneum(TC) and L. serricorne (LS) adults.

\begin{tabular}{cccccc}
\hline Insect & Treatment & $\mathrm{LC}_{50}(95 \% \mathrm{FL})(\mathrm{mg} / \mathrm{L}$ air $)$ & Slope $\pm \mathrm{SE}$ & Chi square $\left(\chi^{2}\right)$ & $p$-value \\
\hline \multirow{4}{*}{$\mathrm{TC}$} & Essential oil & $13.05(11.81-14.39)$ & $4.37 \pm 0.42$ & 11.39 & 0.998 \\
& 1,8 -Cineole ** & $5.47(4.73-6.17)$ & $3.97 \pm 0.47$ & 25.30 & - \\
& Terpinen-4-ol ** & $3.7(3.3-4.3)$ & $2.49 \pm 0.31$ & 27.56 & 0.233 \\
& MeBr * & 1.75 & - & - & - \\
\hline \multirow{4}{*}{ LS } & Essential oil & $8.04(7.30-8.85)$ & $0.98 \pm 0.10$ & 21.02 & 0.82 \\
& 1,8 -Cineole ** & $5.18(4.63-5.70)$ & $4.84 \pm 0.59$ & 16.79 & \\
& Terpinen-4-ol ** & $1.3(0.8-1.7)$ & $1.50 \pm 0.31$ & 12.44 & 0.963 \\
& Phosphine ** & $9.23 \times 10-3$ & & & - \\
\hline
\end{tabular}

* data from Liu and $\mathrm{Ho}^{16)}$, ** data from Wang et al. ${ }^{22,23)}$ and be got at the same laboratory with author.

Table 3 Contact toxicity of $A$. anethoides essential oil against T. castaneum (TC) and L. serricorne (LS) adults.

\begin{tabular}{cccccc}
\hline Insect & Treatment & $\mathrm{LD}_{50}(95 \% \mathrm{FL})(\mu \mathrm{g} /$ adult $)$ & Slope $\pm \mathrm{SE}$ & Chi square $\left(\chi^{2}\right)$ & $p$-value \\
\hline \multirow{4}{*}{ TC } & Essential oil & $28.80(26.16-31.77)$ & $4.47 \pm 0.43$ & 11.95 & 0.997 \\
& 1,8 -Cineole * & $18.83(17.13-20.69)$ & $4.86 \pm 0.50$ & 16.56 & - \\
& Terpinen-4-ol * & $19.7(17.1-22.7)$ & $2.13 \pm 0.29$ & 19.28 & 0.685 \\
& Pyrethrins * & $0.26(0.22-0.30)$ & $3.34 \pm 0.32$ & 13.11 & 0.925 \\
\hline \multirow{4}{*}{ LS } & Essential oil & $24.03(22.01-26.30)$ & $5.41 \pm 5.06$ & 13.34 & 0.946 \\
& 1,8-Cineole * & $15.58(12.88-18.02)$ & $3.87 \pm 0.55$ & 15.18 & - \\
& Terpinen-4-ol * & $5.4(4.0-6.6)$ & $1.70 \pm 0.30$ & 11.63 & 0.976 \\
& Pyrethrins * & $0.24(0.16-0.35)$ & $1.31 \pm 0.20$ & 17.36 & 0.916 \\
\hline
\end{tabular}

* data from Wang et al. ${ }^{22,23)}$ and be got at the same laboratory with author.

main constituents were similar against $L$. serricorne, for example, $A$. $\operatorname{argry}\left(\mathrm{LC}_{50}=8.04 \mathrm{mg} / \mathrm{L}\right.$ air $)$, A. stolonifera $\left(\mathrm{LC}_{50}=0.99 \mathrm{mg} / \mathrm{L}\right.$ air $)$ and $A$. mongolica $\left(\mathrm{LC}_{50}=6.08 \mathrm{mg} / \mathrm{L}\right.$ air ${ }^{19-211}$. 1,8-Cineole and terpinen-4-ol showed excellent fumigant toxicity (Table 2) against two species of insects. This may be helpful to the fumigant toxicity of the essential oil of $A$. anethoides.

\subsection{Contact toxicity}

The contact toxicity of $A$. anethoides essential oil against $T$. castaneum and $L$. serricorne were listed in Table 3. The results exhibited the essential oil of $A$. anethoides possessed contact toxicity against $T$. castaneum $\left(\mathrm{LD}_{50}=28.80 \mu \mathrm{g} /\right.$ adult $)$ and $L$. serricorne $\left(\mathrm{LD}_{50}=24.03 \mu \mathrm{g} /\right.$ adult). When compared with the positive control, pyrethrins, the essential oil demonstrated more weak toxicity against T. castaneum and L. serricorne. However, compared with other essential oils tested using a similar bioassay in the literature, the essential oil of $A$. anethoides possessed stronger contact toxicity against $T$. castaneum adults, e.g. essential oils of Evodia lepta $\left(\mathrm{LD}_{50}=166.94 \mu \mathrm{g} /\right.$ adult), Citrus wilsonii $\left(\mathrm{LD}_{50}=48.49 \mu \mathrm{g} / \mathrm{adult}\right)^{24,25)}$. On the other hand, the essential oil of A. anethoides showed weaker contact toxicity than the essential oils that their main constituents were similar against $L$. serricorne, for example, $A$. $\operatorname{argry}\left(\mathrm{LC}_{50}=6.42 \mu \mathrm{g} /\right.$ adult $)$ and $A$. mongolica $\left(\mathrm{LC}_{50}=22.32 \mu \mathrm{g} / \text { adult }\right)^{19,21)} \cdot 1,8$-Cineole and terpinen-4-ol showed obvious contact toxicity (Table 3 ) against two species of insects.

\subsection{Repellent activity}

The essential oil of $A$. anethoides exhibited obvious repellent activity against $T$. castaneum and L. serricorne (Fig. 1). The PR values of essential oil were $100 \%$ at the testing concentrations of 78.63 and $15.73 \mathrm{~nL} / \mathrm{cm}^{2}$ against $T$. castaneum at $2 \mathrm{~h}$ and $4 \mathrm{~h}$ after exposure, meanwhile the $\mathrm{PR}$ values of essential oil were same level with DEET at five testing concentrations against $T$. castaneum at $2 \mathrm{~h}$ and $4 \mathrm{~h}$ after exposure, even the PR values of essential oil were $45 \%$ at the lowest testing concentrations of $0.13 \mathrm{~nL} / \mathrm{cm}^{2}$ against $T$. castaneum at $2 \mathrm{~h}$. The results indicated the essential oil of $A$. anethoide possessed approximate repellency activity with positive control DEET against $T$. castaneum. The essential oil of $A$. anethoides showed same 

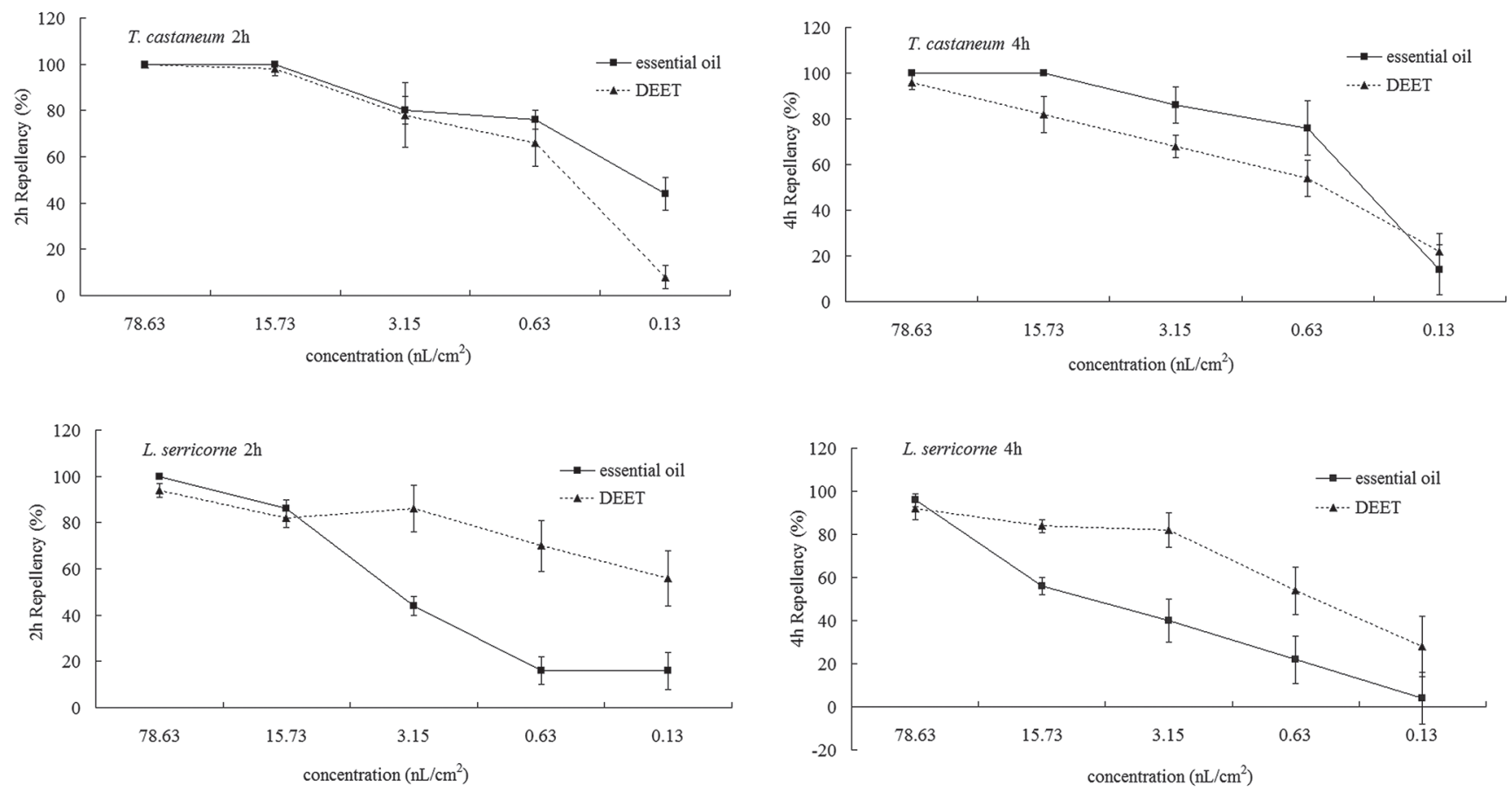

Fig. 1 Percentage repellency of DEET and the essential oil of A. anethoides against T. castaneum and L. serricorne at $2 \mathrm{~h}$ and $4 \mathrm{~h}$ after exposure.

repellent activity level with DEET at the testing concentrations of 78.63 and $15.73 \mathrm{~nL} / \mathrm{cm}^{2}$ at $2 \mathrm{~h}$ after exposure against $L$. serricorne. The PR values of essential oil were more low than DEET at others low testing concentrations against $L$. serricorne. The repellent activity of essential oil was more obvious against T. castaneum than L. serricorne.

\section{CONCLUSION}

The repellency method is one of common pest control, the essential oil of $A$. anethoides exhibited excellent repellency activity against $T$. castaneum and $L$. serricorne. Meanwhile it showed certain fumigant and contact toxicity against two species of insects. The essential oil of $A$. anethoides possessed potential insecticidal and repellent affect for control of insects. Now many biopesticide products have entered the market. For example, there are about 400 registered biopesticides active ingredients and over 1250 products in the United States, and the biopesticides has been substantial growth in recent years, but they still comprise less than $4 \%$ of the global pesticides market ${ }^{26)}$. Like other crop protection technologies, biopesticides also will become smarter through research and innovation.

\section{ACKNOWLEDGMENT}

This project was supported by the Beijing Municipal Natural Science Foundation(No. 7142093) and Fundamental Research Funds for the Central Universities. The authors thank Dr. Liu Q.R. from College of Life Sciences, Beijing Normal University, Beijing 100875, for the identification of the investigated medicinal herb.

\section{References}

1) Abdelghany, A.Y.; Awadalla, S.S.; Abdel-Baky, N.F.; ElSyrafi, H.A.; Fields, P.G. Stored-product insects in botanical warehouses. J. Stored Prod. Res. 46, 93-97 (2010).

2) Mitra, A.; Chatterjee, C.; Mandal, F.B. Synthetic chemical pesticides and their effects on birds. Res. J. Environ. Toxicol. 5, 105-108(2011).

3) Dubey, N.K.; Srivastavab, K.A. Current status of plant products as botanical pesticides in storage pest management. J. Bio. Pest. 1, 182-186 (2008).

4) Isman, M.B. Botanical insecticides, deterrents, and repellents in modern agriculture and an increasingly regulated world. Annu. Rev. Entomol. 51, 45-66 (2006).

5) Casida, J.E.; Quistad, G.B. Golden age of insecticide research: past, present, or future? Annu. Rev. Entomol. 43, 1-16 (1998).

6) Isman, M.B. Perspective botanical insecticides: For 
richer, for poorer. Pest Manag. Sci. 64, 8-11 (2008).

7) Rajendran, S.; Srianjini, V. Plant products as fumigants for stored-product insects control. J. Stored. Prod. Res. 44, 126-135(2008).

8) Ahmadi, M.; Abd-alla, A.M.; Moharramipour, S. Combination of gamma radiation and essential oils from medicinal plants in managing $T$. castaneum contamination of stored products. Appl. Radiat. Isotopes. 78, 16-20 (2013).

9) Chu, S.S.; Liu, S.L.; Liu, Q.Z.; Jiang, G.H.; Liu, Z.L. Chemical composition and insecticidal activities of the essential oil of the flowering aerial parts of Aster ageratoides. J. Serb. Chem. Soc. 78, 209-216(2013).

10) Liang, Y.; Li, J.L.; Xu, S.; Zhao, N.N.; Zhou, L.; Cheng, J.; Liu, Z.L. Evaluation of repellency of some Chinese medicinal herbs essential oils against $L$. bostrychophila (Psocoptera: Liposcelidae) and T. castaneum (Coleoptera: Tenebrionidae). J. Econ. Entomol. 106, 513-519 (2013).

11) Stroh, J.; Wan, M.T.; Isman, M.B.; Moul, D.J. Evaluation of the acute toxicity to juvenile Pacific coho salmon and rainbow trout of some plant essential oils, a formulated product, and the carrier. B. Environ. Contam. Tox. 60, 923-930 (1998).

12) Yang, K.; Wang, C.F.; You, C.X.; Geng, Z.F.; Sun, R.Q.; Guo, S.S.; Du, S.S.; Liu, Z.L.; Deng, Z.W. Bioactivity of essential oil of Litsea cubeba from China and its main compounds against two stored product insects. $J$. Asia-Pac. Entomol. 17, 459-466(2014).

13) You, C.X.; Yang, K.; Wu, Y.; Zhang, W.J.; Wang, Y.; Geng, Z.F.; Chen, H.P.; Jiang, H.Y.; Du, S.S.; Deng, Z.W.; Liu, Z.L. Chemical composition and insecticidal activities of the essential oil of Perilla frutescens (L.) Britt. aerial parts against two stored product insects. Eur. Food. Res. Technol. 239, 481-490 (2014).

14) Delectis Florae Reipublicae Popularis Sinicae Agendae Academiae Sinicae Edita. Flora of China, Tomus 76 (2). Sci. Press., Beijing, pp. 33-34(1999).

15) Adams, R.P. Identification of essential oil components by gas chromatography/quadrupole mass spectroscopy. Allured: Carol Stream, IL, USA (2001).

16) Liu, Z.L.; Ho, S.H. Bioactivity of the essential oil extracted from Evodia rutaecarpa Hook f. et Thomas against the grain storage insects, Sitophilus zeamais Motsch. and Tribolium castaneum (Herbst). J. Stored. Prod. Res. 35, 317-328(1999).

17) Zhang, J.S.; Zhao, N.N.; Liu, Q.Z.; Liu, Z.L.; Du, S.S.;
Zhou, L.; Deng, Z.W. Repellent constituents of essential oil of Cymbopogon distans aerial parts against two stored-product insects. J. Agric. Food Chem. 59, 9910-9915(2011).

18) Sakuma, M. Probit analysis of preference data. Appl. Entomol. Zool. 33, 339-347(1998).

19) Zhang, W.J.; Yang, K.; You, C.X.; Chen, R.; Wang, C.F.; Wu, Y.; Geng, Z.F.; Chen, H.P.; Jiang, H.Y.; Su, Y.; Lei, N.; Ma, P.; Du, S.S.; Deng, Z.W. Bioactivity of essential oil of Artemisia argyi Lévl. et Van. and its main compounds against Lasioderma serricorne. J. Oleo Sci. 63, 829-837 (2014).

20) Zhang, W.J.; Yang, K.; You, C.X.; Wang, Y.; Wang, C.F.; Wu, Y.; Geng, Z.F.; Su, Y.; Du, S.S.; Deng, Z.W. Bioactivity of essential oil from Artemisia stolonifera (Maxim.) Komar. and its main compounds against two stored-product insects. J. Oleo Sci. 64, 299-307 (2015).

21) You, C.X.; Zhang, W.J.; Yang, K.; Guo, S.S.; Geng, Z.F.; Du, S.S.; Wang, C.F.; Deng, Z.W. Identification of repellent and insecticidal constituents Artemisia mongolica essential oil against Lasioderma serricorne. J. Chem. 2015, 1-7(2015).

22) Wang, Y.; You, C.X.; Wang, C.F.; Yang, K.; Zhang, W.J.; Liu, Z.L.; Du, S.S.; Deng, Z.W.; Geng, Z.F. Chemical constituents and insecticidal activities of the essential oil from Amomum tsaoko against two stored-product insects. J. Oleo Sci. 63, 1019-1026(2014).

23) Wang, Y.; You, C.X.; Yang, K.; Wu, Y.; Chen, R.; Zhang, W.J.; Liu, Z.L.; Du, S.S.; Deng, Z.W.; Geng, Z.F. Bioactivity of essential oil of Zingiber purpureum Rhizomes and its main compounds against two stored product insects. J. Econ. Entomol. 108, 925-932 (2015).

24) Jiang, C.H.; Liu, Q.Z.; Du, S.S.; Deng, Z.W.; Liu, Z.L. Essential oil composition and insecticidal activity of Evodia lepta (Spreng) Merr. root barks from China against two grain storage insects. J. Med. Plants Res. 6, 3464-3469 (2012).

25) Chen, H.P.; Yang, K.; You, C.X.; Du, S.S.; Cai, Q.; He, Q.; Geng, Z.F.; Deng, Z.W. Chemical constituents and biological activities against Tribolium castaneum (Herbst) of the essential oil from Citrus wilsonii leaves. J. Serb. Chem. Soc. 79, 1213-1222(2014).

26) Gefei, H.; Guangfu, Y. Pest control: risks of biochemical pesticides. Science 342, 798-799 (2013). 